\title{
Post-Traumatic Stress Disorder in Militaries of Peacekeeping Missions in Areas of Wars and Conflicts
}

\author{
Phd. Eglantina Dervishi ${ }^{1}$ \\ Phd. Candidate, Silva Ibrahimi ${ }^{1}$ \\ Phd.Candidate, Hazir Elshani ${ }^{1}$ \\ ${ }_{1}^{1}$ ssychology Department, Albanian University, Albania \\ Email: egladervishi@gmail.com
}

Doi:10.5901/ajis.2015.v4n2s2p11

\begin{abstract}
The purpose of this study is to identify whether the symptoms of post-traumatic stress are present on peacekeeping missions millitaries who are deployed in areas of armed conflict and which are the variety of post-traumatic stress symptoms in this contingency of militars. The present study is an explorative type based on quantitative data collected by Symptom Checklist 90 Revised (SCL90-R) in peacekeeping mission militaries deployed in conflicted areas. Data revealed that post-traumatic stress symptoms were not present at the targeted sample,we generarly have the confirmation of a more severe symptomatology at that military category which were more than 3-4 times in peacekeeping missions in comparison with those who were once or twice. Post-traumatic stress symptoms have a low frequency in these missions militaries and they generarly are more obvious in those categories who worked in the field. As well as, another interesting finding relates to the fact that symptoms are more obvious in the military category who served more than two missions.
\end{abstract}

Keywords: Post-traumatic stress, militaries, peacekeeping mission, mental health.

\section{Introduction}

Post-traumatic stress is still a serious problem which encounters military forces (Grieger et al.,2006) who participated in peacekeeping missions in Iraq and Afghanistan. Soldiers of UN peacekeeping missions are frequently exposed to a variety of traumatic events (Herrman, 1999) and stressors (Magruder et al., 2004) as a result of their specific conditions. Post-traumatic stress disorder is one of the most common disorders observed in war veterans ( Savoca \& Rosenheck, 2000; Kennedy et al.,2008; Wood, 2012). The disorder was described as a "psychological and complex trauma expressed in a somatic, cognitive, affective and behavioral state" ( Watts et al., 2013; APA, 2013; CTPSD, 2008; Copeland et al., 2007). The disorder is characterized by intrusive thinking, horrors and flashbacks that relates to past traumatic events, avoidance of memories related to traumas, hypervigilence and sleep disorders. All these could cause a variety of problems in the individual life interfering with force in the most part of daily activities as in the social, work and interpersonal areas.

A direct coping with continuing risky situations, in other researches (Hembree \& Fao, 2003; Resick et al., 2002) revealed tracks of experienced traumas in the everyday of personnel after turning back home. Experienced traumas can be revealed in different aspects of individual's life, shaping the Post-Traumatic Stress Disorder displayed in a variety of symptoms that typically in peacekeeping missions militaries are present in substance abuse, agitation and increase of aggressive behaviors.

Refering to the field studies (Davidson, 2006; Figley \& Leventman,1980; Solomon et al., 1987) it was noted that the traumatic experience feeled by militaries in their peacekeeping missions, intervenes after turning back home in three important aspects by leaving a trace and bringing inconvenience to the person and others in terms of personal, familiar and social levels.

In personal terms, sorrow often takes the form of depression and substance abuse, especially alcohol, petulance, aggresiveness, impulsivity that are shown as symptoms of post-traumatic stress.

In familiar terms, research have discovered a series of important findings concerning the way the occurrence of post-traumatic stress in militaries after turning to the family. Militaries become less open with their partners and have a significant anxiety concerning their privacy (O'Connell et al., 1998), withdrawal, lack of communication with their 
partners (Riggs et al., 1998), increased aggressiveness, child neglect, physical exercise and psychological violence in the effect of alcohol. The presence of these elements is the family environment have surely very negative consequences and interferes in the psychological wellbeing not only of militaries affected by post-traumatic stress, but also on their relatives often becoming the main cause of the increasing number of military divorces (O'Connell et al., 1998) in peacekeeping missions participants category.

Personal and familiar problems have their influence either in the social aspect. As even in relationships with their work and community, these individuals have evident problems, such as lack of correctness in the accomplishment of given tasks, aggravated relationship with colleagues, involvement in querrels in public places etc. In some cases even they have been part of the news stories involved in events of self injuries or to others (Barak, 2005), mainly their relatives. Symptoms of PSTD are not always displayed immediately after the traumatic event. Sometimes it takes weeks, months, or even years before symptoms develop. Not all trauma survived develop PSTD. Eventhought not all the reasons are known why some survivors develop PTSD and others do not. Some of the factors that play a significant role include genetic predisposition, sensibility to anxiety, previous experiences with traumatic situations, the presence of other life stressors, coping skills as well as social support. Many military experience late on set of PTSD symptoms. For different reasons they might not experience at all symptoms of PSTD immediately after military services (missions), or might think these symptoms are normal and ignore them for many years (Fao, 2000) focusing to work or familiar life. For some people, it happens that only after retirement, when there is much more time and less distraction, that they begin feeling a growth of symptoms and the onset might be very troubled. It is important that these experiences might be normalized explaining that many militaries experience late or hiden-sleep symptoms.

\section{Methodology}

The study aims to focus on post-traumatic stress symptoms experienced by militaries in peacekeeping missions. For that reason we are focused in the exploration of the scale of psychological disorders through Global Index of Severity of Symptoms, focusing in the Symptoms Checklist 90 - Revised (SCL90-R). The instrument could be used to assess PTSD in a variety of clinical and research settings. The tool is composed of 90 questions that explore a set of aspects as: Somatization (SOM), Obsessive-Compulsive Behaviour (OC), Interpersonal Sensity (I-S),Depression (DEP), Anxiety (ANX), Hostility (HOS), Phobic Anxiety ( PHOB), Paranoid Ideas (PAR) and Psychotism (PSY) to evaluate psychological symptoms. This self-reported instrument could be administrated in $15-20$ mins.

The sample of the study is composed by $(n=108)$ militaries of the Armed Forces of the Republic of Albania selected in random by the staff who participated in international peacekeeping missions.

\section{Data Analysis}

Every data were realised through Statistical Package for Social Scientist (SPSS.19). Descriptive Statistics are used to analyse data focused on frequency, percentage, mean and deviant standard (SD). Variance analysis for sub-scales between psychological factors was calculated through total scores and the relationship between variables through correlation. Internal consistency was assessed through Crombach alpha a.

\section{Results and Discutions}

The group taken in the study was composed by 108 militaries who had taken part in peacekeeping missions. Demographic data revealed that contigents who were participants in peacekeeping missions were males. The majority of them (50\%) were in the group-age 36- 45 years old and almost (32.4\%) in the group-age, 26-35 years old . Regarding the civic state it was revealed that the majority of peacekeeping missions were married (81\%) and a fewer of them were single (11.1\%). Relating other options percentages were insignificant and for more details please refer to table no. 1. 
Table 1: Descriptive statistic of demographic variables $(\mathrm{N}=108)$

\begin{tabular}{lcc}
\hline Variable & N $=108$ & $\%$ \\
\hline Sex & & \\
Female & 0 & 0.00 \\
Male & 108 & 100.0 \\
Age & & \\
$18-25$ & 11 & 10.2 \\
$26-35$ & 35 & 32.4 \\
$36-45$ & 54 & 50.0 \\
Over 45 & 8 & 7.4 \\
Civic State & & \\
Married & 88 & 81.5 \\
Relationship & 2 & 1.9 \\
Divorced & 6 & 5.6 \\
Single & 12 & 11.1 \\
Widowed & 0 & 0 \\
\hline
\end{tabular}

As the used checklist were non standardized in the Albanian context was realized a prove of internal consistency for each sub-scale which resulted within accepted parametres, increasing in such a way the validity of research study.

On the analysis of variance for every sub-scale referring to the collected scores it was no any significant difference with a statistical significance for sub-scales and psychological troubles reported by peacekeeping missions militaries ( Table no.2).

Table 2: Comparation of the score for the subscale and internal consistency of the SCL-90 subscales $(N=108)$

\begin{tabular}{cccc}
\hline Variable & Mean (SD) & $\boldsymbol{\alpha}$ & Variance \\
\hline SOM & $0.87(0.55)$ & 0.91 & 0.41 \\
O-C & $0.71(0.48)$ & 0.71. & 0.39 \\
INS & $0.82(0.32)$ & 0.77 & 0.38 \\
DEP & $0.72(0.65)$ & 0.73 & 0.33 \\
ANX & $0.76(0.45)$ & 0.76 & 0.36 \\
HOS & $0.87(0.56)$ & 0.83 & 0.42 \\
PHO & $0.66(0.45)$ & 0.69 & 0.53 \\
PAR & $0.84(0.45)$ & 0.87 & 0.48 \\
PSY & $0.68(0.55)$ & 0.75 & 0.32 \\
\hline
\end{tabular}

From the results it is clear that the presence of post-traumatic stress does not pose a concern for militaries in peacekeeping missions, although we have a presence of minimal militaries referring to scores. Results taken by this research are not evident whether they show a real view of the post-traumatic stress in the peacekeeping missions or their report was not given sincerely as showing any kind of weakeness is against the code of militars.

An element which has to be considered in the study relates to the fact that very significative is the relation between post-traumatic stress and participation in 3-4 peacekeeping missions. A part of the militaries who had been taken part in peacekeeping missions for more than twice display a

great presence of post-traumatic stress symptoms, which makes us reflect more on their participation times in these missions. Interaction between psychological troubles and the number of participation in peacekeeping missions were analyzed through Pearson correlation $(r=.664, p<0.01)$ showing that the more missions militars had taken part the more the presence of post-traumatic stress symptoms.

Table 3: Correlations between general concern and number of missions $\quad(N=108)$

\begin{tabular}{clcc}
\hline & \multicolumn{1}{c}{ Correlations } & Global severity index & $\begin{array}{c}\text { No.of peacekeeping } \\
\text { missions 3-4 times } \\
\text { Global severity index }\end{array}$ \\
& $\begin{array}{l}\text { Pearson correlation } \\
\text { Sig.(2-tailed) }\end{array}$ & 1 & $.664^{-}$ \\
& N & 108 & .000 \\
No.of peacekeeping & Pearson correlation & $.664^{-}$ & 108 \\
missions 3-4 times & Sig.(2-tailed) & .000 & 1 \\
& N & 108 & 108 \\
\cline { 2 - 2 } & \multicolumn{2}{c}{} \\
& \multicolumn{2}{c}{13}
\end{tabular}


Suggestions for future studies in the aspect relates to considering that military life dynamics have their communication and behavior code, so,it is necessary that other tools might be developed to have a complete overview of the presence of post-traumatic stress in the present sample, to help and support the relief of symptoms on time.

\section{Conclusion}

Post -traumatic stress is still a concern for specialists who work in the treatment of symptoms in war veterans. This being based on the fact that these symptoms do not always appear immediately after the event but also to the fact that these symptoms often hidden from others, the military does not speak for them. Their mistreatment obviously affect individual life in many aspects, as in personal, familiar and professional one. Eventhough the study had difficulties in the reveal of data for the presence of post-traumatic stress in the peacekeeping missions. Interesting results relates to the significant presence between the militaries who served in more than two peacekeeping missions in comparison with those who had been once or twice. Also, a part of them declares experiencing a higher level of stress but do not value the factor as a concerning one. What is of concern is that the tendency not to express might severe their mental state and direct to other pathologies part of the post-traumatic stress as depression and substance addiction. The present data should be taken into consideration by the Armed Forces directors relating the participation of militaries in peacekeeping missions, to avoid the affection of post-traumatic stress in their militaries.

\section{Reference}

American Psychiatric Association. Diagnostic and Statistical Manual of Mental Disorders (5th ed.). Arlington, VA:American Psychiatric Association, 2013.

Barak, Y., et al. 2005. "Increased Risk of Attempted Suicide Among Aging Holocaust Survivors? American Journal of 'GeriatricPsychiatry 13(8): $701-4$.

Committee on Treatment of Posttraumatic Stress Disorder. Treatment of Posttraumatic Stress Disorder: An Assessmentof the Evidence. Washington, DC: The National Academies Press, 200.

Copeland WE, Keeler G, Angold A, Costello J. Traumatic events and posttraumatic stress in childhood. Arch GenPsychiatry 2007; 64: 577-584

Davidson, E. H. 2006. "Late-Life Emergence of Early-Life Trauma: The Phenomenon of Late-Onset Stress SymptomatologyAmong Aging Combat Veterans." Research on Aging 28(1): 84-114.

Figley, C. R., and Leventman, S. 1980. Strangers at Home: Vietnam Veterans Since the War. New York: Praeger

Foa, E.B. (2000). Psychosocial treatment of posttraumatic stress disorder. Journal of Clinical Psychiatry, 61(Suppl. 5), 43-48.

Grieger TA, Cozza SJ, Ursano RJ, Hoge C, Martinez PE, Engel CC, et al . Posttraumatic stress disorder and depression inbattle-injured soldiers. Am J Psychiatry 2006;163:1777-83.

Hembree EA, Foa EB. Interventions for traumarelated emotional disturbances in adult victims of crime. J Trauma Stress 2003; 16: 187-199.

Herrmann N, Eryavec G. Posttraumatic stress disorder in institutionalized World war II veterans. Am J Geriatr Psychiatry1999;2:324-31.

Kennedy, J., Jaffee, M. S., Leskin, G. A., Stokes, J. W., Leal, F. O., \& Fitzpatrick, R J. (2007). Posttraumatic stress disorder andposttraumatic stress disorderlike symptoms and mild traumatic brain injury. Journal of Rehabilitation Research andDevelopment, 44(7), 895-920.

Magruder KM, Frueh BC, Knapp RG, Johnson MR, Vaughan JA 3 [sup]rd, Carson TC, et al . PTSD symptoms,demographic characteristics, and functional status among veterans treated in VA primary care clinics. J Trauma Stress2004;17:293-301.

O'Connell MJ, Kasprow W, Rosenheck RA. Rates and risk factors for homelessness after successful housing in a sample offormerly homeless veterans. Psychiatr Serv 2008;59:268-75

Resick PA, Nishith P, Weaver TL, Astin MC, Feuer CA. A comparison of cognitive-processing therapy with prolongedexposure and a waiting condition for the treatment of chronic posttraumatic stress disorder in female rape victims. J ConsultClin Psychol 2002; 70: 867-879.

Riggs DS, Byrne CA, Weathers FW, Litz BT. The quality of the intimate relationships of male Vietnam veterans: Problemsassociated with posttraumatic stress disorder. J Trauma Stress 1998;11:87-101.

Savoca E, Rosenheck R. The civilian labor market experiences of Vietnam-era veterans: The influence of psychiatricdisorders. J Ment Health Policy Econ 2000;3:199-207.

Solomon, Z., Mikulincer, M., Freid, B., \& Wosner, Y. (1987). Family characteristics and post-traumatic stress disorder: A followup of Israeli Combat Stress Reaction causalities. Family Process, 26, 383-394

Watts BV, Schnurr PP, Mayo L, Young-Xu Y, Weeks WB, Friedman MJ. Meta analysis of the efficacy of treatments forposttraumatic stress disorder. J Clin Psychiatry 2013;74(6):e541-e550. [http://dx.doi.org/10.4088/JCP.12r08225].

Wood, D. (2012, July 4). Iraq, Afghanistan war veterans struggle with combat trauma. Huffington Post. Retrieved fromhttp://www.huffingtonpost.com/2014/07/04/iraq-afghanistan-war-veteranscombat- trauma_n_1645701.html 